\title{
Effects of estrogens and progestagens on the primary variables of haemostasis
}

\author{
Eliana Ibrahimi ${ }^{1,2 *}$, Mynyr Koni ${ }^{1}$
}

\author{
${ }^{1}$ Department of Biology, Faculty of Natural Sciences, University of Tirana, Albania \\ ${ }^{2}$ Ana Diagnostic Center, Tirana, Albania
}

Received: 26 January 2014

Accepted: 2 February 2014

\author{
*Correspondence: \\ Dr. Eliana Ibrahimi, \\ E-mail: eliana.ibrahimi@yahoo.com
}

(C) 2014 Ibrahimi E et al. This is an open-access article distributed under the terms of the Creative Commons Attribution Non-Commercial License, which permits unrestricted non-commercial use, distribution, and reproduction in any medium, provided the original work is properly cited.

\begin{abstract}
Background: The present study aims at determining the effect of two combined oral contraceptives on the primary variables of haemostasis in a group of healthy Albanian women.

Methods: In this study were included, 49 women between the ages of 24 and 51 years, twenty nine of them taking ethinylestradiol $30 \mu \mathrm{g}$ and gestodene $75 \mu \mathrm{g}$ and twenty of them taking ethinylestradiol $30 \mu \mathrm{g}$ and levonorgestrel $75 \mu \mathrm{g}$ for 1-2 months. The subjects had no history of thromboembolic disease. Plasma was used for measuring levels of PT, fibrinogen, factors V and VIII, before and after pill use. Collected data were analyzed using SPSS 20 software.

Results: Comparison of values of the parameters before and after treatment showed that concentrations of fibrinogen and factor VIII were significantly increased following treatment $(p<0.05)$, while we noted no significant changes in the level of factor V. Prothrombin time and activated thromboplastin time were reduced during treatment $(\mathrm{p}>0.05)$.

Conclusions: The results show that changes in the haemostatic primary variables after combined oral contraceptive administration are significant which might increase the risk for thrombotic situations.
\end{abstract}

Keywords: Estrogens, Progestagens, Blood coagulation, Factor VIII, Factor V

\section{INTRODUCTION}

The massive use of female hormones for birth control began in the 1960 s with the availability of oral contraceptives. It is estimated that worldwide 100 million women use an oral contraceptive. ${ }^{1}$ With such a large number of women taking OC, even the smallest increase in risk of side effects will affect the lives of many. Female hormones have a variety of side effects, of which thrombosis is the most frequent and most important. ${ }^{2}$ Knowledge of such risks and efforts to reduce them are of crucial importance.

It is also known that the use of combined hormonal contraceptives (containing both estrogen and progestogen) is associated with an increased risk of venous thromboembolic events. ${ }^{1}$
The first thrombotic side effect of oral contraceptives was reported in 1961, when a nurse developed pulmonary embolism after starting an oral contraceptive containing $100 \mu \mathrm{g}$ oestrogen (mestranol) and norethynodrel as progestogen. ${ }^{3}$ For a long time, it was believed that oestrogens in postmenopausal hormone replacement therapy had no effect on thrombosis, or would even lower the risk, even though early studies in men for whom oestrogens were tried as treatment for coronary disease showed an increased risk of thrombosis. ${ }^{4}$ It was later reported that oestrogens in hormone replacement therapy also increase the risk of venous thrombosis. ${ }^{5}$

Thrombotic risk was reduced when so-called low-dose oral contraceptives containing $50 \mu \mathrm{g}$ or less of estradiol became available. However, a number of subsequent epidemiological studies ${ }^{6}$ suggested that women who use 
third generation pill containing the progestagens desogestrel (DSG) or gestodene (GSD) may have higher risk of venous thrombosis than women who use a second generation oral contraceptive (OC) containing levonorgestrel (LNG). The further increased thrombotic risk in third generation OC users was, however, questioned in later publications. ${ }^{7,8,9}$ The discussion that followed was hampered by the fact that there was neither a good biological explanation for the thrombotic effect of the pill nor for the difference in risk between second and third generation oral contraceptives. ${ }^{10}$

The present study aimed at determining the effect of two combined oral contraceptives (containing ethinyl estradiol and levonorgestrel or gestodene) on five primary haemostatic variables in a group of healthy Albanian women.

\section{METHODS}

\section{Study design}

The investigation was conducted at Ana Diagnostic Center in Tirana, Albania. All participants signed an informed consent form before were included in the study. Healthy women requesting contraception were included and followed up for two months, while smokers and those with contraindications to combined oral contraceptives (COCs) were not followed up for this study. Twenty women were instructed to use COC with $30 \mu \mathrm{g}$ EE and $75 \mu \mathrm{g}$ GSD and 16 were instructed to use COC with 30 $\mu \mathrm{g} \mathrm{EE}$ and $75 \mu \mathrm{g} \mathrm{LNG})$, initiating pill intake on the first day of the cycle. Clinical and laboratory assessments were carried out prior to initiation of medication and after 2 months of COC use.

\section{Laboratory methods}

All participants were submitted to a blood collection to perform the APTT, PT, fibrinogen, factor V and factor VIII laboratory test. Blood samples were centrifuged at $1500 \mathrm{rev} / \mathrm{min}$ for $15 \mathrm{~min}$ to extract plasma. APTT, PT, fibrinogen, factor $\mathrm{V}$ and factor VIII were measured using coagulometry (BFT II analyzer, kits and reagents from Siemens Diagnostic Healthcare, Marburg, Germany).

\section{Statistical analysis}

Student's $t$-test for paired samples was used for numerical variables with normal distribution to compare values of the coagulation factors at two time intervals (pretreatment and after 2 months of COC use). Data are given as mean and $\mathrm{SD}, \mathrm{p}<0.05$ was considered statistically significant. SPSS 20 software was used for running all statistical calculations.

\section{RESULTS}

Mean and SD of the parameters before and after treatment with COCs are reported in Table 1. Paired samples T-test showed that concentrations of fibrinogen and factor VIII were significantly higher after two months of treatment with $30 \mu \mathrm{g}$ EE/75 $\mu \mathrm{g}$ GSD than prior to treatment. Similar results were obtained with treatment with $30 \mu \mathrm{g} \mathrm{EE} / 75 \mu \mathrm{g}$ LNG in the level of FVIII, while the increasing of fibrinogen was not significant $(\mathrm{p}>0.05)$. Prothrombin time (PT), activated partial thromboplastin time (APTT) and FV were significantly reduced in women taking $30 \mu \mathrm{g}$ EE/75 $\mu \mathrm{g}$ GSD, though there was no significant change in this variables in women taking 30 $\mu \mathrm{g} \mathrm{EE} / 75 \mu \mathrm{g}$ LNG (Table 1).

Statistical analysis indicated difference in the effect of different COCs on the levels of APTT, fibrinogen, PT, $\mathrm{FV}$ and the same effect on F VIII level.

\section{DISCUSSION}

In the present study, users of third generation combined oral contraceptives showed significant changes in the primary haemostatic variables. The changes were within the normal range and are not associated with an increase in VTE risk. The results found a large effect of oestrogen and progestogen on some of the variables. A greater change in FV, FVIII, APTT, fibrinogen and PT was observed in the GSD group compared with the LNG group, but we must also take in account that the baseline for these variables was different between groups. In two other studies ${ }^{8,11}$ comparing COCs containing GSD with those containing LNG, there were no significant changes in PT between the two groups.

Table 1: Effects of COCs on the primary variables of haemostasis.

\begin{tabular}{|lllllll|}
\hline \multicolumn{2}{l}{ 30 EE/ 75 GSD } & \multicolumn{3}{c|}{ 30 EE/ 75 LNG } \\
\hline Parameters & Baseline & After COC use & p value & Baseline & After COC use & p value \\
\hline PT (s) & $11.5 \pm 0.4$ & $10.3 \pm 0.6$ & 0.000 & $11.3 \pm 0.9$ & $11.9 \pm 1.4$ & 0.165 \\
\hline APTT (s) & $31.4 \pm 4.4$ & $27.6 \pm 1.5$ & 0.000 & $28.7 \pm 1.8$ & $28.6 \pm 2.5$ & 0.867 \\
\hline FV (\%) & $110.3 \pm 9.3$ & $98.6 \pm 11.6$ & 0.000 & $86.7 \pm 8.1$ & $86.5 \pm 10.8$ & 0.196 \\
\hline FVIII $(\%)$ & $107.1 \pm 8.1$ & $115.03 \pm 14.6$ & 0.01 & $86.6 \pm 9.8$ & $102.8 \pm 10.0$ & 0.000 \\
\hline Fibrinogen $(\mathrm{g} / \mathrm{l})$ & $2.8 \pm 0.2$ & $3.5 \pm 0.3$ & 0.000 & $2.7 \pm 0.77$ & $3.2 \pm 0.64$ & 0.06 \\
\hline
\end{tabular}


Factor VIII was increased after two months of treatment with both COCs. High factor VIII, and fibrinogen levels have been found to be related with a thrombophilic situation. ${ }^{12,13,14}$ Nevertheless, it is important to note that changes observed in coagulation parameters during the use of COCs by healthy women cannot explain the increased risk of thromboembolic disease; hence caution should be taken in interpreting results in aspects of clinical trial.

\section{CONCLUSION}

In conclusion, the use of a COCs containing $30 \mu \mathrm{g}$ EE/75 $\mu \mathrm{g}$ GSD and $30 \mu \mathrm{g} \mathrm{EE} / 75 \mu \mathrm{g}$ LNG for a period of two months in healthy women with no associated risk factors caused significant changes in the primary haemostatic parameters suggestive of a higher prothrombotic risk. The clinical significance of these findings should be established in a larger study with associated risk factors, such as smoking, and over a longer period of COC use.

\section{ACKNOWLEDGEMENTS}

The authors are grateful to the staff of Ana Diagnostic Center laboratory and clinic, and Faculty of Natural Sciences, University of Tirana for providing the financial means and laboratory facilities for this study.

\section{Funding: None}

Conflict of interest: None declared

Ethical approval: Not required

\section{REFERENCES}

1. World Health Organization. Cardiovascular Disease and Steroid Hormone Contraception. Report of a WHO Scientific group. WHO Technical Report, 1998. Series 877. Geneva: World Health Organization.

2. Lemaitre RN, Heckbert SR, Psaty BM, Smith NL, Kaplan RC, Longstreth WT Jr. Hormone replacement therapy and associated risk of stroke in postmenopausal women. Archives of Internal Medicine 2002;162: 1954-1960.

3. Jordan WM. 1961. Pulmonary embolism. Lancet ii, 1146-1147.

4. Jick SS, Jick H. The contraceptive patch in relation to ischemic stroke and acute myocardial infarction. Pharmacotherapy 2007;.27(2): 218-20.

5. Rossouw JE, Anderson GL, Prentice RL, Lacroix AZ, Kooperberg C,Stefanick ML, Jackson RD, Beresford SA, Howard BV, Johnson KC, Kotchen JM, Ockene J. Writing Group for the Women's Health Initiative Investigators. Risks and benefits of estrogen plus progestin in healthy postmenopausal women: principal results from the Women's Health Initiative randomized controlled trial. Journal of the American Medical Association 2002;288:321-33.
6. World Health Organization. Scientific group meeting on cardiovascular disease and steroid hormone contraceptives. Weekly Epidemiological Record 1995;72:361-3.

7. Baillargeon JP, McClish DK, Essah PA, Nestler JE. Association between the current use of low-dose oral contraceptives and cardiovascular arterial disease: a meta-analysis. The Journal of Clinical Endocrinology \& Metabolism 2005;90:3863-70.

8. van Hylckama Vlieg A, Helmerhorst FM, Vandenbroucke JP, Doggen CJ, Rosendaal FR. The venous thrombotic risk of oral contraceptives, effects of oestrogen dose and progestogen type: results of the MEGA case-control study. British Medical Journal 2009;339: b2921, http://dx.doi.org/10.1136/bmj.b2921.

9. Parkin L, Sharples K, Hernandez RK, Jick SS. Risk of venous thromboembolism in users of oral contraceptives containing drospirenone or levonorgestrel: nested case-control study based on UK General Practice Research Database. British Medical Journal, 2011:342: d2139, http://dx.doi.org/10.1136/bmj.d2139.

10. Lidegaard O, Lokkegaard E, Svendsen AL, Agger C. Hormonal contraception and risk of venous thromboembolism: national follow-up study. British Medical Journal 2009:339: 2890. http://dx.doi.org/10.1136/bmj.b28.

11. Prasad RNV, Koh SCL, Osborn AC, Viegas MD, Shan Ratnam S. Effect on hemostasis after two-year use of low dose combined oral contraceptives with gestodene or levonorgestrel. Clinical and Applied Thrombosis/Hemostasis 1999:60-70.

12. Jick SS, Hagberg KW, Hernandez RK, Kaye JA. Postmarketing study of ORTHO EVRA and levonorgestrel oral contraceptives containing hormonal contraceptives with $30 \mathrm{mcg}$ of ethinyl estradiol in relation to nonfatal venous thromboembolism. Contraception 2010;81:16-21.

13. Gronich N, Lavi I, Rennert G. Higher risk of venous thrombosis associated with drospirenone-containing oral contraceptives: a population-based study. Canadian Medical Association Journal 2011;183:319-25.

14. Jick SS, Hernandez RK. Risk of non-fatal venous thromboembolism in women using oral contraceptives containing drospirenone compared with women using oral contraceptives containing levonorgestrel: case-control study using United States claims data. British Medical Journal 2011; 342: d2151, http://dx.doi.org/10.1136/bmj.d2151.

DOI: $10.5455 / 2320-1770$. ijrcog20140305

Cite this article as: Ibrahimi E, Koni M. Effects of estrogens and progestagens on the primary variables of haemostasis. Int J Reprod Contracept Obstet Gynecol 2014;3:31-3. 